\title{
Thermal Behaviour of Common Thermoresponsive Polymers in Phosphate Buffer and in Its Salt Solutions
}

\author{
Łukasz Otulakowski, Maciej Kasprów, Aleksandra Strzelecka, Andrzej Dworak and Barbara Trzebicka *D \\ Centre of Polymer and Carbon Materials, Polish Academy of Sciences, M. Curie-Skłodowskiej 34 \\ 41-819 Zabrze, Poland; lotulakowski@cmpw-pan.edu.pl (Ł.O.); mkasprow@cmpw-pan.edu.pl (M.K.); \\ astrzelecka@cmpw-pan.edu.pl (A.S.); adworak@cmpw-pan.edu.pl (A.D.) \\ * Correspondence: btrzebicka@cmpw-pan.edu.pl
}

Citation: Otulakowski, Ł.; Kasprów, M.; Strzelecka, A.; Dworak, A.; Trzebicka, B. Thermal Behaviour of Common Thermoresponsive Polymers in Phosphate Buffer and in Its Salt Solutions. Polymers 2021, 13,

90. https://doi.org/10.3390/ polym13010090

Received: 28 November 2020 Accepted: 22 December 2020 Published: 28 December 2020

Publisher's Note: MDPI stays neutral with regard to jurisdictional clai$\mathrm{ms}$ in published maps and institutional affiliations.

Copyright: (C) 2020 by the authors. Licensee MDPI, Basel, Switzerland. This article is an open access article distributed under the terms and conditions of the Creative Commons Attribution (CC BY) license (https:// creativecommons.org/licenses/by/ $4.0 /)$.
Abstract: Thermoresponsive polymers are a promising material for drug nanocarrier preparation, which makes the study of their aggregation in physiological conditions very important. In this paper, the thermal behaviour of the thermoresponsive polymers poly( $N$-isopropylacrylamide), poly(2-isopropyl-2-oxazoline-co-2-n-propyl-2-oxazoline) and poly[(2-hydroxyethyl methacrylate)-cooligo(ethylene glycol) methyl ether methacrylate] were studied in phosphate buffer (PBS) and solutions of its salts in concentration as in PBS. The thermal response of the polymers was measured using UV-Vis and dynamic light scattering (DLS). The salts shifted the cloud point temperature $\left(\mathrm{T}_{\mathrm{CP}}\right)$ of the (co)polymers to higher values compared to the $\mathrm{T}_{\mathrm{CP}}$ of aqueous polymer solutions. In $\mathrm{PBS}$ and $\mathrm{NaCl}$ solutions, all polymers exhibited an unexpected and previously unreported transmittance profile. During heating, an additional aggregation of polymers appeared above the $\mathrm{T}_{\mathrm{CP}}$ accompanied by the formation of a precipitate. In monosodium phosphate solutions and pure water, the studied polymers showed lower critical solution temperature (LCST-type) behaviour. DLS measurements showed that a salt influenced the size of the resulting polymer particles. The sizes and stability of particles depended on the heating rate. In PBS and $\mathrm{NaCl}$ solutions, the size of particles in the dispersion decreased above $60^{\circ} \mathrm{C}$, and the precipitate appeared on the bottom of the cuvette. The additional aggregation of polymer and its falling out of solution may hinder the removal of carriers from the body and has to be taken into account when preparing nanocarriers.

Keywords: thermoresponsive polymers; poly( $N$-isopropylacrylamide); poly[oligo(ethylene glycol) methacrylate]; polyoxazoline; phosphate buffer; salts; aggregation; solution chemistry

\section{Introduction}

Thermoresponsive polymers have been studied for several decades because of their unique properties of undergoing reversible soluble-insoluble or insoluble-soluble phase transitions in solution in response to changes in environmental temperatures. A transition appears above a certain temperature called the cloud point temperature $\left(\mathrm{T}_{\mathrm{CP}}\right)$. Lower critical solution temperature (LCST-type) thermoresponsive polymers, in a dilute aqueous solution above $\mathrm{T}_{\mathrm{CP}}$, form well-defined spherical particles called mesoglobules [1-3]. The size of the mesoglobules depends on various factors such as the polymer molar mass, solution concentration, heating protocol and the presence of additives such as salts [4] and surfactants [5-7]. Of the group of polymers that undergo a thermal transition during heating, the most thoroughly examined are poly $(N$-isopropylacrylamide) (PNIPAM) [8-11], polyoxazolines [12-15] and oligo(ethylene glycol) methacrylates (OEGMA) (co)polymers [16-18].

It is well known that the salts present in a thermoresponsive polymer solution may alter its $\mathrm{T}_{\mathrm{CP}}$ [19-21]. Extensive studies on the influence of both organic and inorganic salts on the behaviour of macromolecules in a salt solution were done by Hofmeister [22]. All salts have been divided into one of two groups: kosmotropic and chaotropic salts, which cause 
"salting in" and "salting out" effects, respectively. In the case of a polymer solution, the presence of salts changes the hydration sphere of polymer chains and, in consequence, changes the polymer solubility. Traditionally, the relative effects of anions present in solution on the physical behaviour of polymers have been ranked according to the Hofmeister series: $\mathrm{CO}_{3}{ }^{2-}>\mathrm{SO}_{4}{ }^{2-}>\mathrm{S}_{2} \mathrm{O}_{3}{ }^{2-}>\mathrm{HPO}_{4}{ }^{2-}>\mathrm{H}_{2} \mathrm{PO}_{4}{ }^{-}>\mathrm{F}^{-}>\mathrm{Cl}^{-}>\mathrm{Br}^{-}>\mathrm{NO}_{3}{ }^{-}>\mathrm{I}^{-}>$ $\mathrm{ClO}_{4}{ }^{-}>\mathrm{SCN}^{-}$. The order of the Hofmeister series is valid only for a uniform concentration of anions. Chaotropic anions, such as $\mathrm{SCN}^{-}, \mathrm{ClO}_{4}{ }^{-}$and I ${ }^{-}$, show a "salting in" effect leading to an increase of $\mathrm{T}_{\mathrm{CP}}$; i.e., an increase of polymer solubility. Chaotropic salts in a water solution can disrupt the hydrogen bonding network between water molecules. This affects the stability of the state of macromolecules in solution by weakening the hydrophobic effect. Consequently, water molecules favorably interact with the polymers or proteins and stabilise the intramolecular interactions within these macromolecules [23]. On the other hand, kosmotropic anions lead to a "salting out" effect that arises from a decrease of the $\mathrm{T}_{\mathrm{CP}}$ of the thermoresponsive polymers (a decrease of polymer solubility). Kosmotropic salts contribute to the stability and structure of water-water interactions. Both "salting in" and "salting out" effects are enhanced by an increase in salt concentration [24].

The influence of the addition of salt on the shifting transition temperature of the thermoresponsive polymers has been previously studied for PNIPAM [25], poly(2-ethyl2-oxazoline) [26], poly(2-n-propyl-2-oxazoline) [26], poly(2-isopropyl-2-oxazoline) [26], poly[oligo(ethylene glycol) methacrylate] [20] and others [27]. There are only rare cases in which the behaviour of thermoresponsive polymers in the presence of salts during heating above $\mathrm{T}_{\mathrm{CP}}$ has been reported [28]. Although changes of the thermoresponsive polymers' $\mathrm{T}_{\mathrm{CP}}$ values in the presence of salts have been investigated $[4,19,25,26]$, there are no studies on the effect of salts on the aggregation process and particle formation. Recently, Gubarev et al. [29] demonstrated the rigidity changes of poly(2-ethyl-2-oxazoline)s chains during heating in physiological conditions.

Bruce and coworkers [30] used molecular dynamic simulations to explain the complex behaviour of PNIPAM in a solution of a mixture of two salts, namely $\mathrm{NaCl}$ and $\mathrm{NaSO}_{4}$. The collapse and subsequent swelling processes of PNIPAM in solution with increasing salt concentrations were ascribed to changes in the water affinity of anions present in the solution and an increase in the ion-pairing affinity between $\mathrm{SO}_{4}{ }^{-}$and $\mathrm{Na}^{+}$. The authors showed that the effect of salts on the $\mathrm{T}_{\mathrm{CP}}$ of PNIPAM was non-additive.

The high potential of thermoresponsive polymers as drug carriers results from the possibility of controlling the thermal aggregation leading to the formation of particles; a second important aspect is the simple procedure of the stabilisation of the particles obtained as a result [31-34]. In this regard, the behaviour of thermoresponsive polymers in solutions containing components present in the biological medium is essential. The medium usually used in biological studies is phosphate buffer (PBS). PBS is isotonic and non-toxic to most cells and is used as a medium to simulate physiological $\mathrm{pH}$ in different research studies. However, the behaviour of thermoresponsive polymers in PBS is seldom described in the literature $[4,19,25,35,36]$.

Several studies have found that the behaviour of thermoresponsive polymers in PBS solution is typical for LCST-type polymers [35,36]. Nishimori et al. [35] reported transmittance changes of PNIPAM in a $5 \mathrm{mM}$ PBS solution. The temperature-dependence curve of transmittance was sigmoidal. Nagase et al. studied the thermoresponsive behaviour of NIPAM and $N, N^{\prime}$-dimethylaminopropyl acrylamide or $N, N^{\prime}$-dimethylacrylamide copolymers in Dulbecco's phosphate saline, which has a more complex composition than traditional PBS [36]. The polymer transmittance plots did not indicate changes in transmittance above $\mathrm{T}_{\mathrm{CP}}$, and the curve was also sigmoidal.

However, other studies have shown that a subsequent aggregation and precipitation of polymers above $\mathrm{T}_{\mathrm{CP}}$ were observed [37,38]. Longenecker et al. [37] described the thermoresponsive properties of various copolymers of HEMA and cationic monomers. In the case of poly[(2-hydroxyethyl) methacrylate-co-methacrylic acid] in aqueous solution containing sodium chloride, the authors observed an increase of solution transmittance 
during heating above the $\mathrm{T}_{\mathrm{CP}}$ and the appearance of a sludge. A similar behaviour of poly[(ethylene glycol) methyl ether acrylate-co-(methoxy ethoxy ethyl) acrylate] in PBS solution was reported but not discussed by the authors [38].

In our previous work [39], the synthesis and thermal behaviour of a set of poly[(2hydroxyetyl)methacrylate-co-oligo(ethylene glycol) methacrylate] (P(HEMA-co-OEGMA $\left.{ }_{300}\right)$ ) copolymers weredescribed. In PBS, the copolymers showed thermal transitions followed by a significant transmittance increase above $\mathrm{T}_{\mathrm{CP}}$. The increase of transmittance was accompanied by additional polymer aggregation and the formation of a transparent gel.

In most cases, the envisaged application of thermoresponsive polymers is in medicine and biology, where the polymer particles work in physiological solutions of a complex composition.

Possible future applications in medicine, our previous results and the gap in the reported literature motivated us to systematically study the temperature behaviour and aggregation of representative thermoresponsive (co)polymers poly( $N$-isopropylacrylamide) (PNIPAM), poly(2-isopropyl-2-oxazoline-co-2-n-propyl-2-oxazoline) (P(IPO-co-NPO)) and poly[2-hydroxyethyl methacrylate-co-oligo(ethylene glycol) methyl ether methacrylate] $\left(\mathrm{P}\left(\mathrm{HEMA}-\mathrm{co}-\mathrm{OEGMA} \mathrm{A}_{300}\right)\right)$ in phosphate buffer solutions. We have also tested the aforementioned polymers in solutions of a single salt presented in PBS to determine which salts are responsible for the formation of the observed polymer precipitation upon heating above $\mathrm{T}_{\mathrm{CP}}$. The aggregation process of thermoresponsive chains and the sizes of particles formed under slow and abrupt heating were discussed.

\section{Materials and Methods}

\subsection{Materials}

Phosphate buffer saline $10 \times$ concentrate (PBS) (after dilution c $=0.1 \mathrm{M}$, containing sodium phosphate and sodium chloride as supplier inform), monosodium phosphate monohydrate $\geq 99.0 \%\left(\mathrm{NaH}_{2} \mathrm{PO}_{4}{ }^{*} \mathrm{H}_{2} \mathrm{O}\right)$, disodium phosphate heptahydrate $98.0-102.0 \%$ $\left(\mathrm{Na}_{2} \mathrm{HPO}_{4} * 7 \mathrm{H}_{2} \mathrm{O}\right)$, and sodium chloride $\geq 99.5 \%(\mathrm{NaCl})$ were purchased from SigmaAldrich (Hamburg, Germany) and used as received. PNIPAM $\left(\mathrm{M}_{\mathrm{n}}=67,000 \mathrm{~g} / \mathrm{mol}\right.$ and $\mathrm{M}_{\mathrm{w}} / \mathrm{M}_{\mathrm{n}}=1.8$ ) was purchased from Sigma-Aldrich (Hamburg, Germany) and used as received. $\mathrm{P}(\mathrm{IPO}-\mathrm{co}-\mathrm{NPO})\left(\mathrm{M}_{\mathrm{n}}=51,000 \mathrm{~g} / \mathrm{mol}\right.$ and $\left.\mathrm{M}_{\mathrm{w}} / \mathrm{M}_{\mathrm{n}}=1.3\right)$ was synthesised via cationic ring-opening polymerisation initiated by methyl 4-nitrobenzenesulfonate at the Centre of Polymer and Carbon Materials, Polish Academy of Sciences, as previously shown in [40]. P(HEMA-co-OEGMA ${ }_{300}$ ) with $79.7 \%$ mol of HEMA and $20.3 \%$ mol of OEGMA $_{300}$ and $M_{n}=33,000 \mathrm{~g} / \mathrm{mol}\left(M_{w} / M_{n}=1.2\right)$ was synthesised at the Centre of Polymer and Carbon Materials at the Polish Academy of Sciences via atom transfer radical polymerisation as described in [39]. The molar mass of polymers was determined using gel permeation chromatography with a multiangle light scattering detector, which was considered to deliver their absolute values.

\subsection{Methods}

\subsubsection{Phosphate Buffer and Salt Solutions Preparation}

The water used to obtain solutions was purified using a commercial ion exchange system (Hydrolab, Straszyn, Poland).

Individual salt solution concentrations corresponding to their concentration in commercial PBS were used. In total, $0.737 \mathrm{~g}(6.14 \mathrm{mmol})$ of monosodium phosphate was placed in a $250 \mathrm{~mL}$ volumetric flask and dissolved in $200 \mathrm{~mL}$ of deionised water. The solution was placed on a mechanical shaker overnight to ensure that the salt completely dissolved into the solution. The next day, water was added to achieve a final volume of $250 \mathrm{~mL}$. The final concentration of $\mathrm{NaH}_{2} \mathrm{PO}_{4}$ in solution was $0.02456 \mathrm{M}$.

The solutions of disodium phosphate and sodium chloride were prepared in the same manner using $2.676 \mathrm{~g} \mathrm{Na}_{2} \mathrm{HPO}_{4}(18.85 \mathrm{mmol})$ and $2.018 \mathrm{~g} \mathrm{NaCl}(34.5 \mathrm{mmol})$. The final concentrations were $0.0754 \mathrm{M}$ for the $\mathrm{Na}_{2} \mathrm{HPO}_{4}$ solution and $0.137 \mathrm{M}$ for the $\mathrm{NaCl}$ solution. 


\subsubsection{Polymer Solutions Preparation}

Each studied polymer was dissolved in water, PBS and the single salt solutions. In all solutions, the polymer concentration was $0.5 \mathrm{~g} / \mathrm{L}$. To ensure complete dissolution of the polymers, the solutions were placed in a refrigerator at $4{ }^{\circ} \mathrm{C}$ overnight.

\subsubsection{Turbidity Measurements}

The $\mathrm{T}_{\mathrm{CP}}$ values in the prepared solutions were determined using a SPECORD 200 PLUS UV-Vis spectrophotometer (Analytik Jena) (Jena, Germany) with a Peltier temperaturecontrolled cell holder. The samples were measured at a constant transmittance wavelength $(\lambda=550 \mathrm{~nm})$. The polymer solutions at a concentration of $0.5 \mathrm{~g} / \mathrm{L}$ were heated from $20^{\circ} \mathrm{C}$ to $70{ }^{\circ} \mathrm{C}$ at a heating rate of $1{ }^{\circ} \mathrm{C} / \mathrm{min}$. Afterwards, the samples were cooled to $25^{\circ} \mathrm{C}$ at a cooling rate of $1^{\circ} \mathrm{C} / \mathrm{min}$. The $\mathrm{T}_{\mathrm{CP}}$ value was determined by the temperature at which the transmittance of the polymer solution reached $50 \%$ of the difference of transmittance above and below the transition.

\subsubsection{Characterisation by Dynamic Light Scattering}

Dynamic light scattering was used to follow the aggregation process that occurred under the influence of temperature and to determine the sizes of the aggregated structures. The measurements were recorded using a Brookhaven BI-200 (Brookhaven Instruments Corporation, Holtsville, NY, USA) goniometer with vertically polarised incident light of wavelength $\lambda=637 \mathrm{~nm}$ (semiconductor laser diode $36 \mathrm{~mW}$ ) and equipped with a Brookhaven BI-9000 AT digital autocorrelator (Brookhaven Instruments Corporation, Holtsville, NY, USA). The intensity of scattered light was measured at an angle of $90^{\circ}$. The autocorrelation functions were analysed using the constrained regularised inverse Laplace transform (CONTIN program) method to obtain the distributions of the relaxation rates $(\Gamma)$. The latter provided distributions of the apparent diffusion coefficient $D$ $\left(D=\Gamma / q^{2}\right.$, where $q$ is the magnitude of the scattering vector, $q=(4 \pi n / \lambda) \sin (\theta / 2)$, and $n$ is the refractive index of the medium). The apparent hydrodynamic radius $\left(R_{\mathrm{h}}^{90}\right)$ was obtained from the Stokes-Einstein equation (Equation (1)):

$$
R_{\mathrm{h}}^{90}=\frac{k T}{6 \pi \eta D}
$$

for $\theta=90^{\circ}$, where $k$ is the Boltzmann constant and $\eta$ is the viscosity of water at temperature $T$. The dispersity (D) of the particle diameters was given as $\mu_{2} / \bar{\Gamma}^{2}$, where $\bar{\Gamma}$ is the average relaxation rate and $\mu_{2}$ is its second moment.

The rate of heating used in slow heating DLS experiments ranged between 0.3 and $0.5^{\circ} \mathrm{C} / \mathrm{min}$.

\section{Results and Discussion}

Because of their easily tailored properties, response to thermal stimuli in the normal human body temperature range and biocompatibility, PNIPAM, polyoxazolines and HEMA copolymers were considered to be of interest as potential drug carriers.

$\mathrm{N}$-isopropylacrylamide was used to synthesise many thermoresponsive (co)polymers. Some of these copolymers were conjugated with bioactive species, such as peptides, proteins and drugs [41-45]. The thermal behaviours of PNIPAM and its copolymers have been widely studied in water but rarely tested in PBS [44,46,47].

The thermal and crystalline properties of thermoresponsive poly(2-oxazoline)s have been the subject of many works [48-50]. The random P(IPO-co-NPO) has been examined in a water environment and exhibited no hysteresis or second aggregation upon heating above $\mathrm{T}_{\mathrm{CP}}[51]$.

Thermoresponsive P(HEMA-co-OEGMA) has been synthesised by our group and characterised with special attention paid to its behaviour in water and PBS solutions. The control of the HEMA content in the copolymer allowed us to tune the $\mathrm{T}_{\mathrm{CP}}$ [39]. 
As was discussed in the introduction, the properties of thermoresponsive polymers in water solutions have been the subject of numerous studies. However, their behaviour in a salt environment similar to that found in the human body has still not been studied in detail and is not fully understood.

\subsection{Turbidity Studies}

The thermal behaviours of thermoresponsive PNIPAM, P(IPO-co-NPO) and P(HEMAco-OEGMA ${ }_{300}$ ) with $79.7 \% \mathrm{~mol}$ of HEMA and $20.3 \% \mathrm{~mol}$ of $\mathrm{OEGMA}_{300}$ were studied using UV-Vis in PBS and its individual salt solutions. The heating from $20^{\circ} \mathrm{C}$ to $70^{\circ} \mathrm{C}$ (well above the $\mathrm{T}_{\mathrm{CP}}$ of studied polymers) and then cooling procedures were used. The experiments were repeated 3-5 times with preprepared samples. The transmittance was measured for the solutions with a total polymer concentration of $0.5 \mathrm{~g} / \mathrm{L}$. To determine the effect of individual salts on the behaviour of the polymers, solutions with salt concentrations corresponding to the concentration in PBS were used.

In addition, polymers were tested in pure water according to the same procedures as those used for salt solutions to compare the transition temperatures in the respective media. The transmittance vs. temperature curves for the polymers in water were sigmoidal (Figure S1). The cooling curves almost overlapped with the heating curves, indicating full reversibility of thermal aggregation. The $\mathrm{T}_{\mathrm{CP}}$ values determined for the polymers in water are given in Table 1 . As can be expected, the obtained $\mathrm{T}_{\mathrm{CP}}$ values are in good agreement with those previously reported $[39,40,52]$.

Table 1. Cloud point temperature $\left(\mathrm{T}_{\mathrm{CP}}\right)$ of polymers in different solutions depicted from UV-vis traces. PNIPAM: poly(N-isopropylacrylamide); P(IPO-co-NPO): poly(2-isopropyl-2-oxazoline-co-2-npropyl-2-oxazoline); P(HEMA-co-OEGMA 300 ): poly[2-hydroxyethyl methacrylate-co-oligo(ethylene glycol) methyl ether methacrylate].

\begin{tabular}{cccccc}
\hline & \multicolumn{5}{c}{$\mathrm{T}_{\mathrm{CP}}\left({ }^{\circ} \mathrm{C}\right)$ by UV-Vis } \\
\hline (Co)Polymer & Water & PBS & $\begin{array}{c}\mathbf{N a H}_{2} \mathbf{P O}_{4} \\
\text { Solution }\end{array}$ & $\begin{array}{c}\mathbf{N a}_{2} \mathrm{HPO}_{4} \\
\text { Solution }\end{array}$ & NaCl Solution \\
\hline PNIPAM & 35.0 & 32.0 & 34.0 & 34.0 & 32.0 \\
P(IPO-co-NPO) & 28.5 & 27.0 & 28.0 & 27.5 & 27.5 \\
P(HEMA-co- & 46.0 & 44.5 & 45.5 & 43.0 & 39.5 \\
OEGMA300) & & & & & \\
\hline
\end{tabular}

The course of the transmittance curves shown in Figure 1 indicates the polymers behaved quite differently when placed in PBS.
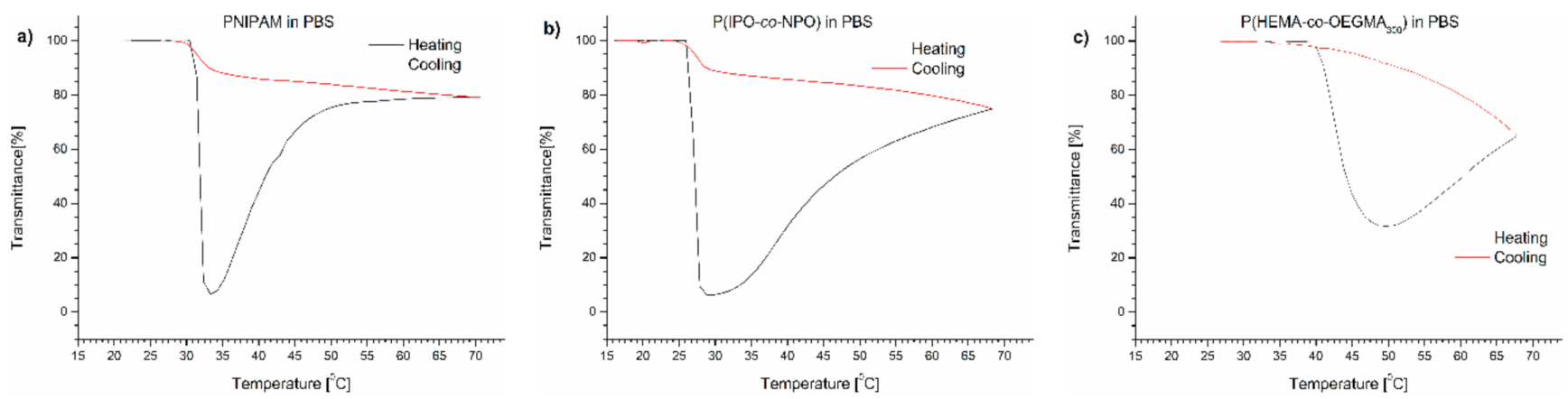

Figure 1. Transmittance versus temperature curves of PBS solutions of (a) PNIPAM, (b) P(IPO-co-NPO) and (c) P(HEMA-co$\mathrm{OEGMA}_{300}$ ). Total solute concentration: $0.5 \mathrm{~g} / \mathrm{L}$; heating/cooling rate: $1^{\circ} \mathrm{C} / \mathrm{min}$. Heating: black; cooling: red.

The transmittance curves of each of the polymers tested were not sigmoidal during heating, but after passing $\mathrm{T}_{\mathrm{CP}}$, the curve reached a minimum. A further elevation of temperature led to a pronounced increase of transmittance of the dispersions. The dispersion 
became transparent, indicating a decrease of the particle number in the volume "visible" by the UV beam. The dispersions were not allowed to anneal at high temperatures but cooled immediately after reaching $70^{\circ} \mathrm{C}$. The transmittance curves upon cooling at the same rate $\left(1{ }^{\circ} \mathrm{C} / \mathrm{min}\right)$ did not follow the profile of the heating curves and lay greatly above the latter. The transmittance increased to the initial value with decreasing temperature.

It was observed that when the temperature increased above the transition temperature, the (co)polymers started to precipitate (Figure 2 and Figure S2). The precipitate was stable at elevated temperatures and dissolved only after storing the vials in the fridge.

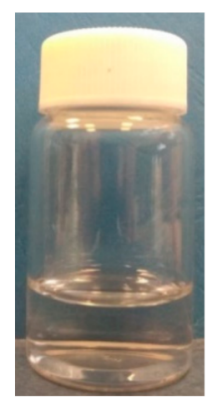

(a)

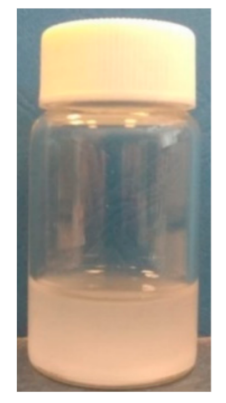

(b)

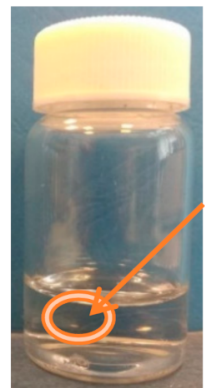

(c)

Figure 2. Solution of $\mathrm{P}(\mathrm{HEMA}-\mathrm{co}-\mathrm{OEGMA} 300)$ in PBS at different temperatures: (a) room temperature, (b) cloud point temperature (c) at $70{ }^{\circ} \mathrm{C}$ (the arrow and circle show the formed gel). Concentration of solution: $0.5 \mathrm{~g} / \mathrm{L}$.

Figure 2 shows the changes in the P(HEMA-co-OEGMA ${ }_{300}$ ) solution in PBS during heating. A transparent solution was observed at room temperature (Figure $2 a$ ). Figure $2 b$ depicts the cloudy polymer dispersion achieved just above $\mathrm{T}_{\mathrm{CP}}$. An increase in the temperature above the minimum of transmittance led to a clearing of the dispersion and formation of a gel (Figure 2c).

The $\mathrm{T}_{\mathrm{CP}}$ of the (co)polymers in PBS was determined as the value at which the transmittance of the polymer solution reached $50 \%$ of the value between the maximum and the minimum of transmittance. The $\mathrm{T}_{\mathrm{CP}}$ values are presented in Table 1. In all cases, the transition temperatures of the polymers in PBS were shifted toward lower temperatures compared to pure water. The highest shift of $3{ }^{\circ} \mathrm{C}$ was observed for PNIPAM. The lowering of the $\mathrm{T}_{\mathrm{CP}}$ indicates that water-polymer interactions in $\mathrm{PBS}$ were replaced to some extent by the salt interactions with water, causing a "salting out" effect.

To determine which salt was responsible for the effect of polymer precipitation upon heating, we performed a series of experiments to follow the influence of individual $\mathrm{Na}_{2} \mathrm{HPO}_{4}, \mathrm{NaH}_{2} \mathrm{PO}_{4}$ and $\mathrm{NaCl}$ salts on the (co)polymers' behaviour. The content of the salts in the studied polymer solutions corresponded to their concentration in PBS. The transmittance of PNIPAM, P(IPO-co-NPO) and P(HEMA-co-OEGMA $\left.{ }_{300}\right)$ solutions containing salts are shown in Figures 3-5, respectively.

In the case of PNIPAM dissolved in salt solutions, a minimum on the transmittance curve and additional aggregation at the temperature above were only observed in the presence of $\mathrm{NaCl}$ (Figure $3 \mathrm{c}$ ). The $\mathrm{T}_{\mathrm{CP}}$ values in phosphate salts were slightly shifted towards lower temperatures in comparison with $\mathrm{T}_{\mathrm{CP}}$ in water, but were higher than in PBS (Table 1). The $\mathrm{T}_{\mathrm{CP}}$ of PNIPAM in $\mathrm{NaCl}$ solution was $32{ }^{\circ} \mathrm{C}$, which is equal to the value measured in PBS. An insignificant hysteresis was observed for phosphate PNIPAM solutions, whereas for $\mathrm{NaCl}$, the return curve was similar to that seen in PBS. 

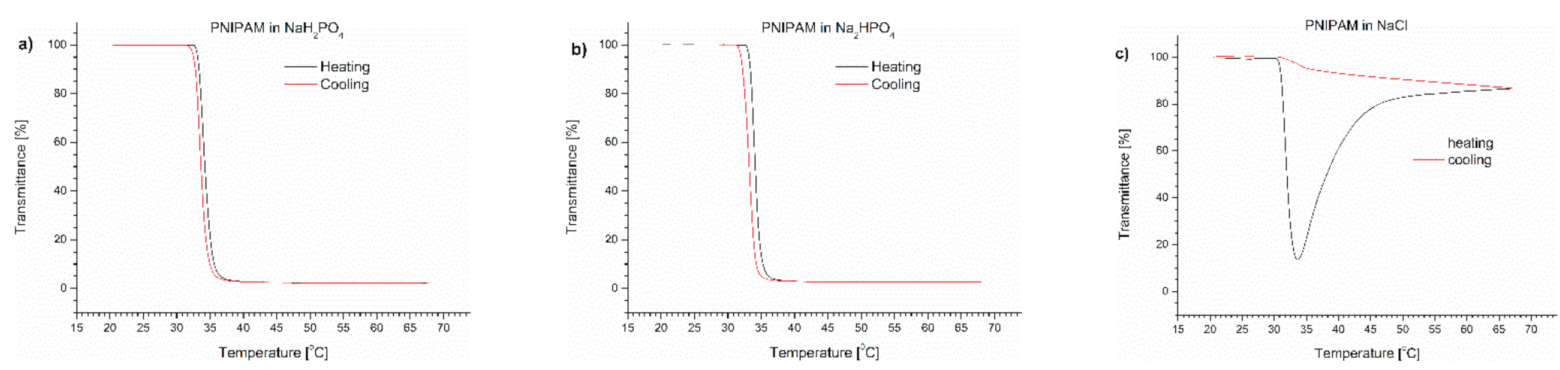

Figure 3. Transmittance versus temperature curves of solutions of PNIPAM in (a) monosodium phosphate, (b) disodium phosphate, (c) $\mathrm{NaCl}$. Total solute concentration: $0.5 \mathrm{~g} / \mathrm{L}$; heating/cooling rate: $1{ }^{\circ} \mathrm{C} / \mathrm{min}$. Heating: black; cooling: red.
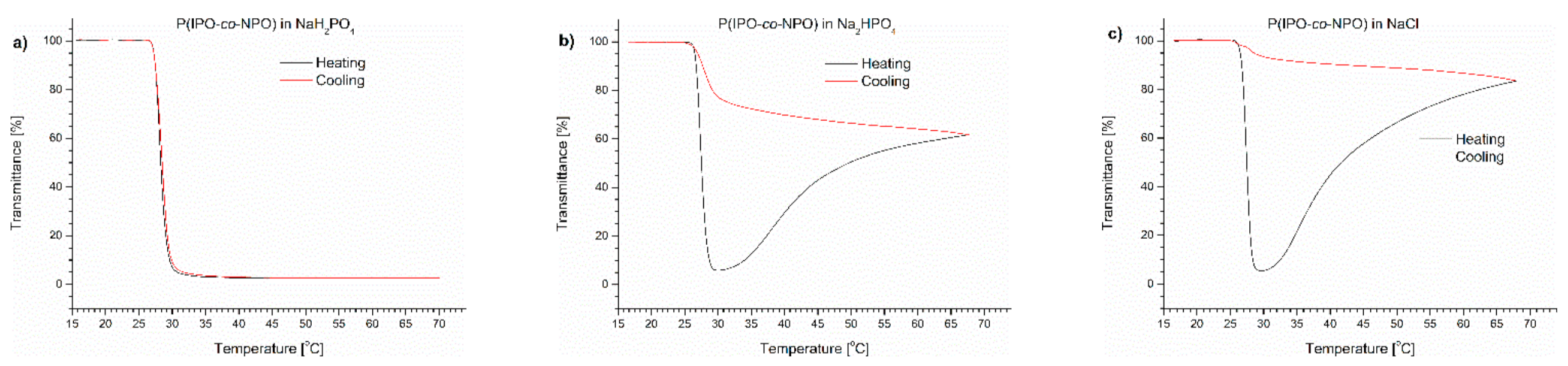

Figure 4. Transmittance versus temperature curves of $\mathrm{P}(\mathrm{IPO}-\mathrm{co}-\mathrm{NPO})$ solutions in (a) monosodium phosphate, (b) disodium phosphate, (c) $\mathrm{NaCl}$. Total solute concentration: $0.5 \mathrm{~g} / \mathrm{L}$; heating/cooling rate: $1{ }^{\circ} \mathrm{C} / \mathrm{min}$. Heating: black; cooling: red.
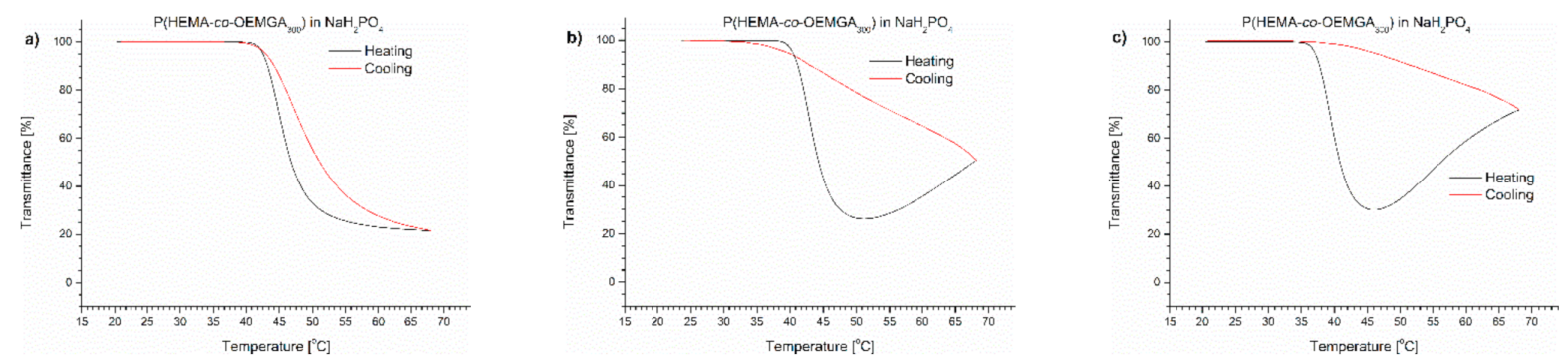

Figure 5. Transmittance versus temperature curves of solutions of $\mathrm{P}\left(\mathrm{HEMA}-\mathrm{co}-\mathrm{OEGMA} \mathrm{A}_{300}\right)$ in $(\mathbf{a})$ monosodium phosphate, (b) disodium phosphate, (c) $\mathrm{NaCl}$. Total solute concentration: $0.5 \mathrm{~g} / \mathrm{L}$; heating/cooling rate: $1^{\circ} \mathrm{C} / \mathrm{min}$. Heating: black; cooling: red.

The P(IPO-co-NPO) copolymer in a monosodium phosphate solution showed a typical LCST-type transition. The transmittance curves for the heating and cooling procedures were sigmoidal and almost overlapped. A precipitation was not observed. The transition temperature of the copolymer in this solution was $0.5^{\circ} \mathrm{C}$ lower than in water. The $\mathrm{T}_{\mathrm{CP}}$ values of the polyoxazoline in $\mathrm{Na}_{2} \mathrm{HPO}_{4}$ and $\mathrm{NaCl}$ solutions were lower than that for the $\mathrm{NaH}_{2} \mathrm{PO}_{4}$ solution (Table 1). Bloksma et al. [26] reported the "salting out" effect for a set of oxazoline (co)polymers in $\mathrm{NaCl}$ solution. The $\mathrm{T}_{\mathrm{CP}}$ depended strongly on the salt concentrations. The nature of the influence of salts on the transition temperature was independent of the type of oxazoline. However, the transmittance curves of polyoxazoline in the presence of $\mathrm{Na}_{2} \mathrm{HPO}_{4}$ and $\mathrm{NaCl}$ resembled those observed for the polymer solution in PBS. After the decrease of transmittance related to an LCST-type transition, the curves went through the minimum and, with a further increase of temperature, a whitish precipitate was formed at the bottom of the vial (Figure 2). When comparing both salts, the effect of the precipitate formation was stronger in the $\mathrm{NaCl}$ solution at $70^{\circ} \mathrm{C}$, and the observed transmittance $(84 \%)$ exceeded the value of the dispersion of polyoxazoline in the presence of $\mathrm{Na}_{2} \mathrm{HPO}_{4}$. 
In the case of P(HEMA-co-OEGMA $\left.{ }_{300}\right)$ with $79.7 \%$ mol of HEMA and $20.3 \%$ mol of $\mathrm{OEGMA}_{300}$, the presence of salts in the solution caused a decrease of $\mathrm{T}_{\mathrm{CP}}$ in the order $\mathrm{NaH}_{2} \mathrm{PO}_{4}(0.02456 \mathrm{M})<\mathrm{Na}_{2} \mathrm{HPO}_{4}(0.0754 \mathrm{M})<\mathrm{NaCl}(0.137 \mathrm{M})<$ pure water solution (Table 1). In $\mathrm{Na}_{2} \mathrm{HPO}_{4}$ and $\mathrm{NaCl}$ solutions, the copolymer precipitation was observed when the temperature was raised above the minimal value (Figure 5 and Figure S2). In the solution of monosodium phosphate, a pronounced hysteresis was visible during the cooling cycle, indicating a possible occurrence of a minimal particle precipitation.

For the all studied salt solutions, except for $\mathrm{NaH}_{2} \mathrm{PO}_{4}$, the precipitation of the thermoresponsive polymers was found. The concentration of salts used in the experiments was imposed by their concentration in PBS. It was clearly shown that $\mathrm{NaCl}$ had the most significant influence on polymer aggregation, but this salt also had the highest concentration in PBS. The differences in the concentration of the studied salts meant that the observed dependences did not fit the salts' relations in the Hofmeister series.

The results of the experiments proved that the influence of salts on polymer aggregation was non-additive.

It should be emphasized that polymer structures formed in salt solutions heated above the minimum cannot be regarded as thermodynamically stable. When the dispersions were held at the selected temperature for a longer time, the transmittance slowly increased.

In separate experiments, the PBS solutions of the studied polymers were heated only to temperatures slightly $\left(1-2{ }^{\circ} \mathrm{C}\right)$ below the minimum value observed on the transmittance curves. This was similar to that observed previously for poly[2-hydroxyethyl methacrylateco-oligo(ethylene glycol) methacrylate] by Kasprów et al. [39]. All of the (co)polymers studied using this procedure showed reversible cloudy-to-transparent phase behaviour with no signs of precipitation.

\subsection{Aggregates Formed by Thermoresponsive (Co)Polymers in PBS and Salt Solutions}

The light scattering experiments of (co)polymer solutions with a concentration of $0.5 \mathrm{~g} / \mathrm{L}$ were performed in PBS and salts present in PBS in the temperature range from 20 to $70{ }^{\circ} \mathrm{C}$. The behaviour of the polymers in water was also studied.

Two protocols - abrupt and slow (gradual) heating-were used. It was noticed that the aggregation of thermoresponsive polymers in the gradual heating process led to particles of sizes significantly larger than those obtained when the solution was heated abruptly. These dependencies were found for a wide range of thermoresponsive polymers, such as copolymers of OEGMA [18] and PNIPAM and its copolymers with a diverse architecture $[11,53,54]$. An increase of the solution heating rate led to a predominance of intra-chain interactions and caused a decrease in the sizes achieved by the aggregates formed in the solution. Particles were formed from polymer chains presented in a set volume of solution. An increase in the heating rate of the solution reduced the contact time; thus, the likelihood of aggregation also decreased.

\subsubsection{Slow Heating Mode}

The hydrodynamic diameters $\left(\mathrm{D}_{\mathrm{h}}{ }^{90}\right)$ of the particles and scattered light intensity $\left(\mathrm{I}^{90}\right)$ were measured at scattering angle of $90^{\circ}$. The results of the DLS studies of the polymer solutions are expressed as $\mathrm{D}_{\mathrm{h}}{ }^{90}$ vs. temperature. On the same plots, changes in scattered light intensity are presented. Slow heating resembled the experimental conditions used in UV-Vis experiments. However, it must be noted that, due to experimental limitations, the rates of heating and cooling in the slow heating protocol differed considerably from those applied in UV-Vis measurements. This caused differences between the experiments, but the results obtained using both methods are complementary.

The diameters of aggregates measured by DLS from all experiments at $70{ }^{\circ} \mathrm{C}$ are summarised in Table S1.

In pure water, the sigmoidal $\mathrm{D}_{\mathrm{h}}{ }^{90} \mathrm{vs}$. temperature dependence was observed for all polymers (Figure S3). The particle sizes and the $\mathrm{I}_{90}$ values remained stable in temperatures above the phase transition, indicating the formation of thermodynamically stable 
dispersions' in water. The smallest particles with a hydrodynamic diameter of $770 \mathrm{~nm}$ were found for PNIPAM (Table S1).

In Figure $6, \mathrm{D}_{\mathrm{h}}{ }^{90}$ and $\mathrm{I}_{90}$ temperature functions of the polymers' dispersions in PBS are presented.
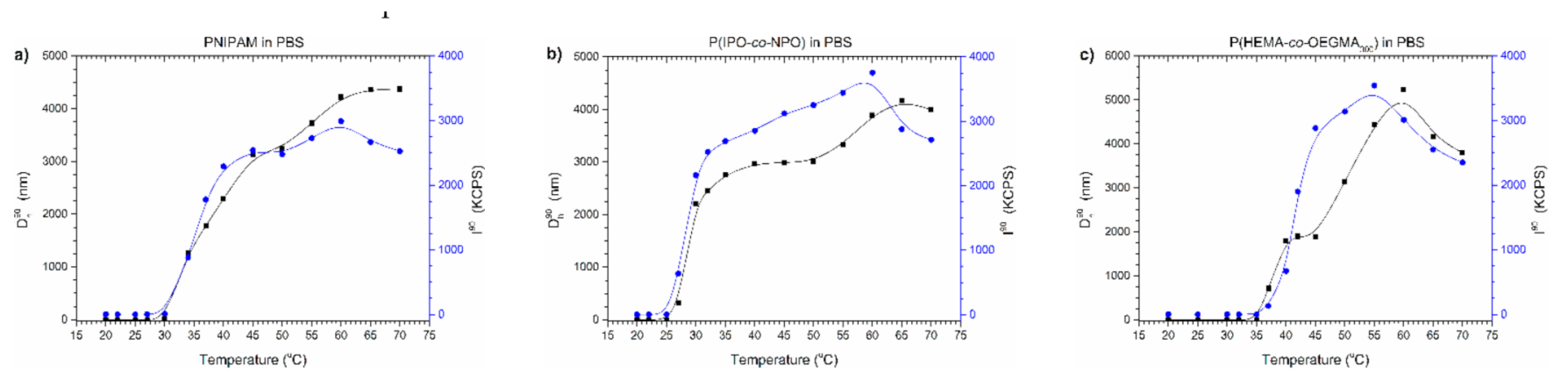

Figure 6. $\mathrm{D}_{\mathrm{h}}{ }^{90}$ and $\mathrm{I}^{90}$ versus temperature plots of solution of (a) PNIPAM, (b) P(IPO-co-NPO) and (c) P(HEMA-co$\mathrm{OEGMA}_{300}$ ) in commercial PBS. Polymer concentration: $0.5 \mathrm{~g} / \mathrm{L}$; gradual heating.

Two transitions can be easily distinguished on the curves during the heating of thermoresponsive polymers in PBS (Figure 6). In the first phase of the aggregation process, the sizes of particles increased, reflecting LCST-type changes. Then, the sizes of particles stabilised, and after exceeding a certain temperature, the particles began to grow again. This increase in particle sizes was accompanied by a decrease in the intensity of scattered light. The observed dependence indicated that the amount of particles present in dispersion decreased. In the DLS experiment, the formation of sludge at the bottom of the vial was noticed, which caused a decrease in particle concentration and, simultaneously, the lowering of scattered light intensity. The observations agreed with data from UV-Vis studies where the polymer precipitated in PBS above the temperature of the minimum transmittance.

Figure 7 contains the distributions of the sizes of aggregates present in the studied polymer dispersions at $70^{\circ} \mathrm{C}$. It can be seen that, in PBS, as a result of heating the polymer chains, particles were formed that were much larger than in water (Table S1, Figure 7).
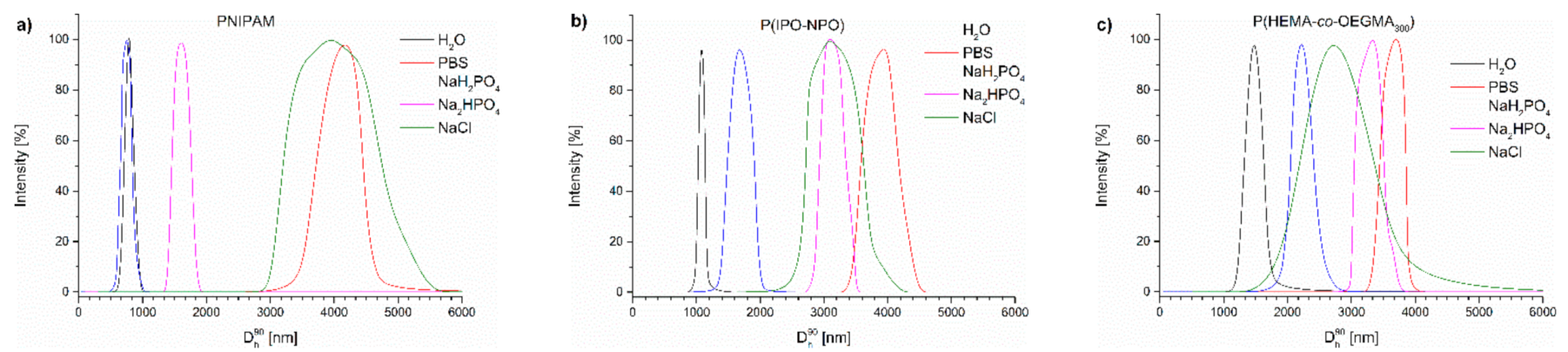

Figure 7. Size distribution of particles of (a) PNIPAM, (b) P(IPO-co-NPO) and (c) P(HEMA-co-OEGMA) acquired by slow heating in different salt solutions at $70{ }^{\circ} \mathrm{C}$.

Further studies were focused on the aggregation of the thermoresponsive polymers in solutions containing only individual salts present in PBS. As in UV-Vis experiments, concentrations of salts were set to match their concentrations in PBS. The results for $D_{h}{ }^{90}$ and light intensity as a function of temperature are shown in Figures S4-S6. Diameters of polymer aggregates at $70{ }^{\circ} \mathrm{C}$ observed in dispersions after gradual heating are shown in Table S1.

In phosphate salt solution, above the phase transition, PNIPAM formed a stable dispersion (Figure $\mathrm{S} 4 \mathrm{a}, \mathrm{b}$ ). The aggregates did not precipitate when the temperature was increased. In $\mathrm{NaH}_{2} \mathrm{PO}_{4}$, the sizes of aggregates were comparable with the sizes observed in 
water (Table S1, Figure S3), whereas in $\mathrm{Na}_{2} \mathrm{HPO}_{4}$, the particles were much larger. However, precipitation did not occur. In the $\mathrm{NaCl}$ solution, PNIPAM formed large aggregates of $4000 \mathrm{~nm}$ immediately after the transition (Figure S4c). This was accompanied by polymer precipitation and the decrease of scattered light intensity. In UV experiments, this behavior was manifested as an increase in transmittance (Figure 2).

The DLS results for P(IPO-co-NPO) (Figure S5), as for PNIPAM, were in good agreement with the transmittance observations as detected by UV-Vis. Above the temperature transition, polyoxazoline dispersion was thermodynamically stable in the $\mathrm{NaH}_{2} \mathrm{PO}_{4}$ solution. In $\mathrm{NaCl}$ and $\mathrm{Na}_{2} \mathrm{HPO}_{4}$, DLS indicated the progressing precipitation of polyoxazoline accompanied by a lowering of $\mathrm{I}^{90}$.

Furthermore, $\mathrm{P}\left(\mathrm{HEMA}-\mathrm{co}-\mathrm{OEGMA}_{300}\right.$ ) particles in a monosodium phosphate exhibited dispersion with heating above the temperature transition (Figure S6a). The dispersions of the copolymer in $\mathrm{NaCl}$ and $\mathrm{Na}_{2} \mathrm{HPO}_{4}$ were not thermodynamically stable (Figure $\mathrm{S} 6 \mathrm{~b}, \mathrm{c}$ ). The size decrease and the precipitate appearance were observed for both salts and were accompanied by a lowering of the intensity of scattering of light.

All studied polymers in the monosodium phosphate salt formed stable particles which did not precipitate. The same was confirmed for the transmittance experiments (Figures 3-5). This could be due to the low concentration of this salt in solution. All copolymer dispersions in $\mathrm{NaCl}$ and $\mathrm{P}(\mathrm{IPO}-\mathrm{co}-\mathrm{NPO})$ and P(HEMA-co-OEGMA dispersions in disodium phosphate) were not stable; their heating above temperature transition led to progressing precipitation.

The changes of particle sizes during heating/cooling runs of thermoresponsive polymer in salt solutions are shown for PNIPAM (Figure S7a-d) as an example. The $D_{h}$ vs. temperature curves reflects a similar dependence to that in UV-Vis spectrophotometric measurements.

\subsubsection{Abrupt Heating Mode}

It has repeatedly been shown that the abrupt, shock heating of a solution of a thermoresponsive polymer results in the formation of well-defined, relatively small and narrowly distributed mesoglobules in comparison to slow heating $[18,55,56]$. Salt solutions of the polymers were subjected to abrupt heating from room temperature to $70^{\circ} \mathrm{C}$, which was well above their transition temperature. The size of particles created using this procedure is shown as a function of time in Figure 8 and listed in Table 2. As an example, the particle size distribution of PNIPAM in salt solutions and water at $70{ }^{\circ} \mathrm{C}$ is presented in Figure S8a. Figure $\mathrm{S} 8 \mathrm{~b}$ shows the changes in the particle distribution in $\mathrm{NaCl}$ with time.
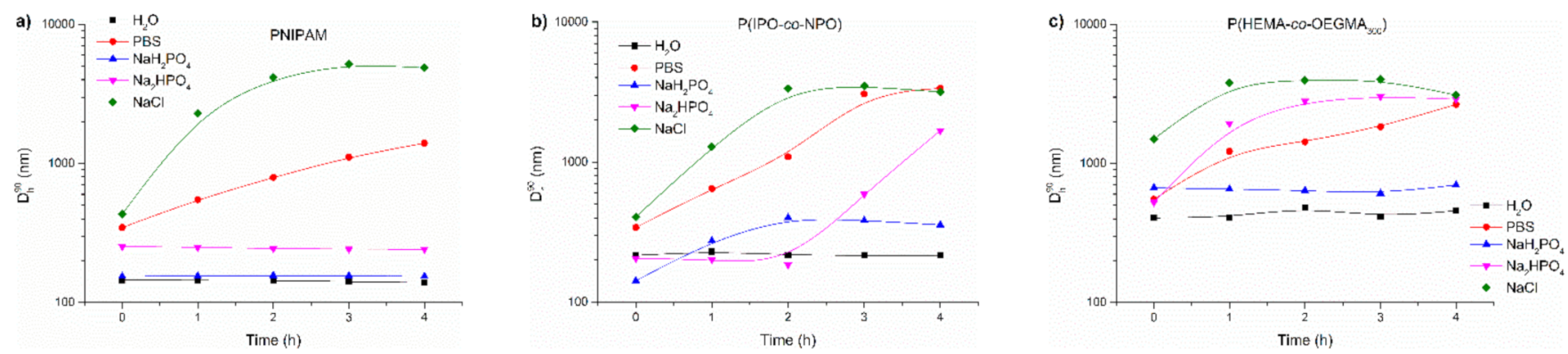

Figure 8. Variations of $\mathrm{D}_{\mathrm{h}}{ }^{90}$ with time for abruptly heated solutions of (a) PNIPAM, (b) P(IPO-co-NPO) and (c) P(HEMA-co$\mathrm{OEGMA}_{300}$ ). Polymer concentration: $0.5 \mathrm{~g} / \mathrm{L}$; abrupt heating at $70^{\circ} \mathrm{C}$. 
Table 2. Polymeric particles sizes in different solutions after abrupt heating and $4 \mathrm{~h}$ of sample annealing at $70{ }^{\circ} \mathrm{C}$.

\begin{tabular}{cccccc}
\hline & \multicolumn{5}{c}{ Hydrodynamic Diameter after $4 \mathbf{h}$ at $\mathbf{7 0}{ }^{\circ} \mathbf{C}(\mathbf{n m})$} \\
\hline Copolymer & Water & PBS & $\begin{array}{c}\mathbf{N a H}_{2} \mathbf{P O}_{4} \\
\text { Solution }\end{array}$ & $\begin{array}{c}\mathbf{N a}_{2} \mathbf{H P O}_{4} \\
\text { Solution }\end{array}$ & $\begin{array}{c}\mathbf{N a C l} \\
\text { Solution }\end{array}$ \\
\hline $\begin{array}{c}\text { PNIPAM } \\
\text { P(IPO-co- }\end{array}$ & 140 & 1400 & 155 & 240 & 4875 \\
$\begin{array}{l}\text { NPO) } \\
\text { P(HEMA-co- }\end{array}$ & 220 & 3360 & 360 & 1680 & 3450 \\
OEGMA300) & 460 & 2660 & 700 & 2900 & 3100 \\
\hline
\end{tabular}

These measurements evidence the thermodynamic instability of the polymer particles in PBS and indicate which PBS salt/salts are responsible for this behavior.

For PNIPAM, the $\mathrm{D}_{\mathrm{h}}{ }^{90}$ vs. time is shown in Figure 8a. The particles formed by PNIPAM chains in water and phosphate salts were stable over time. On the other hand, PNIPAM particles in commercial PBS and $\mathrm{NaCl}$ grew over time, reaching $1400 \mathrm{~nm}$ and $4900 \mathrm{~nm}$ after $4 \mathrm{~h}$, respectively. However, in sodium chloride solutions, the sizes of aggregates decreased when the time of heating exceeded three hours. This was accompanied by polymer precipitation.

The time behaviour of particles formed by $\mathrm{P}(\mathrm{IPO}-\mathrm{co}-\mathrm{NPO})$ in the abrupt heating mode are shown in Figure 8b. In water, P(IPO-co-NPO) aggregates of $220 \mathrm{~nm}$ were created. For the polymer dissolved initially in $\mathrm{PBS}, \mathrm{NaCl}$ and $\mathrm{Na}_{2} \mathrm{HPO}_{4}$, the sizes of aggregates increased with time. Particles in PBS reached ca. $3400 \mathrm{~nm}$ diameter after $4 \mathrm{~h}$. The polymer formed a precipitate at the bottom of the vial. In a monosodium phosphate solution, aggregates of the polyoxazolines increased to $360 \mathrm{~nm}$ and remained stable over time.

As a result of abrupt heating, the chains of $\mathrm{P}\left(\mathrm{HEMA}-\mathrm{co}-\mathrm{OEGMA}_{300}\right)$ formed particles of about $3000 \mathrm{~nm}$ after $4 \mathrm{~h}$ when the copolymer was dissolved in PBS, $\mathrm{NaCl}$ and $\mathrm{Na}_{2} \mathrm{HPO}_{4}$ (Figure 8c). In these solutions, a part of the polymer precipitated after $3 \mathrm{~h}$ of annealing. The aggregates in water and $\mathrm{NaH}_{2} \mathrm{PO}_{4}$ were stable over time but of a significantly larger size than for other thermoresponsive polymers studied here.

When comparing the influence of individual salts on particles formed in the abrupt mode, it can be noticed that $\mathrm{NaH}_{2} \mathrm{PO}_{4}$ at the concentration used in the experiments did not destabilise the dispersions of polymer mesoglobules. In all cases, they were significantly smaller than in gradual heating, but larger than in water. The particles of the studied polymers were not stable in a $0.134 \mathrm{M} \mathrm{NaCl}$ solution and PBS. In these media, the particles grew over time, which led to their precipitation, as in gradual heating.

\section{Conclusions}

In the majority of the reported scientific research, the thermal behaviour of thermoresponsive polymers has been studied in water. The purpose of our research was to follow the temperature response of three chosen representative thermoresponsive polymerspoly( $\mathrm{N}$-isopropylacrylamide), poly(2-isopropyl-2-oxazoline-co-2-n-propyl-2-oxazoline) and poly[2-hydroxyethyl methacrylate-co-oligo(ethylene glycol) methyl ether methacrylate]in PBS, the medium usually used to simulate physiological $\mathrm{pH}$ and used to test polymer behavior in an environment matching that of the human body. Turbidity studies in PBS solutions have shown that the presence of PBS salts lowers the transition temperatures by a few degrees at a polymer concentration of $0.5 \mathrm{~g} / \mathrm{L}$. We have observed, however, that the behavior of tested polymers in PBS is different from that in water. The heating of solutions above the temperature of the minimum transmittance led to subsequent polymer precipitation. The precipitate remains stable during cooling and does not dissolve. Irreversible precipitation reduces the concentration of the polymer in the dispersion in the path of light, which increases the transmittance value above the $\mathrm{T}_{\mathrm{CP}}$. The plots of the heating and cooling cycles do not overlap. To determine which salt was responsible for the precipitation, studies were performed with individual salt solutions at concentrations corresponding 
to their concentration in commercial PBS. For all studied polymers, the precipitation was observed for a $0.137 \mathrm{M} \mathrm{NaCl}$ solution, which was the highest concentration of the tested individual salts. $\mathrm{Na}_{2} \mathrm{HPO}_{4}$ caused the same effect in solutions of polyoxazoline and polymethacrylate, but not of PNIPAM. The resulting precipitates were very durable, but the precipitate dissolved after prolonged storage in temperatures below $\mathrm{T}_{\mathrm{CP}}$.

The polymers' aggregate formation followed by DLS allowed the study of the process of the self-assembly of thermoresponsive chains and the determination of the sizes of particles in dispersions during their abrupt and gradual heating. The particle changes during gradual heating correlated well with the process of transmittance changes. Studies showed that the influence of salt on aggregation depends on the salt ion type, its concentration and the polymers' main chain structure. The results indicated that the effect of the presence of salt is non-additive.

Further detailed research is needed to determine the effect of salt concentration and to explain the phenomenon of the formation of precipitates above the $\mathrm{T}_{\mathrm{CP}}$ of thermoresponsive polymers in the salt solutions. This is of special importance as thermoresponsive polymers are frequently proposed as drug carriers. The results presented in the paper clearly indicate that, for this purpose, the study of the thermal behavior of thermoresponsive polymers should be carried out in an environment close to the physiological environment.

Supplementary Materials: The following are available online at https://www.mdpi.com/2073 $-4360 / 13 / 1 / 90 / s 1$, Figure S1. Transmittance versus temperature curves of aqueous solutions of (a)PNIPAM, (b) P(IPO-co-NPO) (c) P(HEMA-co-OEGMA $\left.{ }_{300}\right)$. Total solute concentration $0.5 \mathrm{~g} / \mathrm{L}$, heating/cooling rate $1^{\circ} \mathrm{C} / \mathrm{min}$. Heating-black, cooling-red; Figure S2. Representative pictures of precipitates formed in $\mathrm{NaCl}$ solution of (a) PNIPAM, (b) P(IPO-co-NPO) (c) P(HEMA-co-OEGMA 300 ); Figure SI3. $\mathrm{D}_{\mathrm{h}}{ }^{90}$ versus temperature plots of water solution of (a)PNIPAM, (b) P(IPO-co-NPO), (c) P(HEMA-co-OEGMA ${ }_{300}$ ). Total solute concentration $0.5 \mathrm{~g} / \mathrm{L}$. Heating-black, cooling-red; Table S1. Diameters of polymers aggregates after gradual heating depicted from DLS at $70{ }^{\circ} \mathrm{C}$; Figure S4. $\mathrm{D}_{\mathrm{h}}{ }^{90}$ and $\mathrm{I}^{90}$ versus temperature plots of PNIPAM in (a) monosodium phosphate, (b) disodium phosphate, (c) sodium chloride solutions. Polymer concentration $0.5 \mathrm{~g} / \mathrm{L}$, gradual heating; Figure S5. $\mathrm{D}_{\mathrm{h}}{ }^{90}$ and $\mathrm{I}^{90}$ versus plots of $\mathrm{P}(\mathrm{IPO}-\mathrm{co}-\mathrm{NPO})$ in (a) monosodium phosphate, (b) disodium phosphate, (c) sodium chloride solutions. Polymer concentration $0.5 \mathrm{~g} / \mathrm{L}$, gradual heating; Figure $\mathrm{S} 6 . \mathrm{D}_{\mathrm{h}}{ }^{90}$ and $\mathrm{I}^{90}$ versus temperature plots of $\mathrm{P}\left(\mathrm{HEMA}-\mathrm{co}-\mathrm{OEGMA}_{300}\right)$ in $(\mathrm{a})$ monosodium phosphate, (b) disodium phosphate, (c) sodium chloride solutions. Polymer concentration $0.5 \mathrm{~g} / \mathrm{L}$, gradual heating; Figure S7. $\mathrm{D}_{\mathrm{h}}{ }^{90}$ versus temperature plots during heating and cooling of PNIPAM in (a) commercial PBS (b) disodium phosphate, (c) sodium phosphate (d) sodium chloride solutions. Polymer concentration $0.5 \mathrm{~g} / \mathrm{L}$, gradual heating; Figure S8. Particles size distribution of PNIPAM in abrupt heating (a) in different solutions after $4 \mathrm{~h}$, (b) in solution of $\mathrm{NaCl}$ after different times periods. Table S1. Diameters of polymer aggregates after gradual heating depicted from DLS at $70{ }^{\circ} \mathrm{C}$.

Author Contributions: Conceptualization, A.D.; Data curation, Ł.O. and M.K.; Funding acquisition, A.S.; Investigation, Ł.O. and M.K.; Methodology, Ł.O., M.K. and B.T.; Project administration, B.T.; Software, A.S.; Supervision, A.D.; Writing—original draft, Ł.O. and M.K.; Writing—review \& editing, A.D. and B.T. All authors have read and agreed to the published version of the manuscript.

Funding: This research received no external funding. It was supported only by state funds for the Centre of Polymer and Carbon Materials, Polish Academy of Sciences.

Institutional Review Board Statement: Not applicable.

Informed Consent Statement: Not applicable.

Data Availability Statement: The data presented in this study are available on request from the corresponding author. The data are not publicly available due to them being part of ongoing project.

Conflicts of Interest: The authors declare no conflict of interest.

\section{References}

1. Aseyev, V.O.; Tenhu, H.; Winnik, F.M. Temperature Dependence of the Colloidal Stability of Neutral AmphiphilicPolymers in Water. In Conformation-Dependent Design of Sequences in Copolymers II; Khokhlov, A.R., Ed.; Springer: Berlin/Heidelberg, Germany, 2006; pp. 1-85. ISBN 978-3-540-32947-3. 
2. Zhang, G.; Wu, C. Folding and Formation of Mesoglobules in Dilute Copolymer Solutions. In Conformation-Dependent Design of Sequences in Copolymers I; Khokhlov, A.R., Ed.; Springer: Berlin/Heidelberg, Germany, 2006; pp. 101-176. ISBN 978-3-540-32946-6.

3. Kretlow, J.D.; Hacker, M.C.; Klouda, L.; Ma, B.B.; Mikos, A.G. Synthesis and Characterization of Dual Stimuli Responsive Macromers Based on Poly(N-isopropylacrylamide) and Poly(vinylphosphonic acid). Biomacromolecules 2010, 11, 797-805. [CrossRef] [PubMed]

4. Zhang, Y.; Furyk, S.; Sagle, L.B.; Cho, Y.; Bergbreiter, D.E.; Cremer, P.S. Effects of Hofmeister Anions on the LCST of PNIPAM as a Function of Molecular Weightt. J. Phys. Chem. C 2007, 111, 8916-8924. [CrossRef] [PubMed]

5. Lee, L.-T.; Cabane, B. Effects of Surfactants on Thermally Collapsed Poly(N-isopropylacrylamide) Macromolecules. Macromolecules 1997, 30, 6559-6566. [CrossRef]

6. Koňák, Č.; Hrubý, M. Thermoresponsive Polymeric Nanoemulsions. Macromol. Rapid Commun. 2006, 27, 877-881. [CrossRef]

7. Otulakowski, L.; Kasprow, M.; Dworak, A.; Trzebicka, B. Effect of sodium dodecyl sulfate on solution behavior of thermoresponsive polymers and their mixtures. Polimery 2019, 64, 469-479. [CrossRef]

8. Eeckman, F.; Moës, A.J.; Amighi, K. Synthesis and characterization of thermosensitive copolymers for oral controlled drug delivery. Eur. Polym. J. 2004, 40, 873-881. [CrossRef]

9. Van Durme, K.; Van Assche, G.; Van Mele, B. Kinetics of Demixing and Remixing in Poly(N-isopropylacrylamide)/Water Studied by Modulated Temperature DSC. Macromolecules 2004, 37, 9596-9605. [CrossRef]

10. Schild, H. Poly(N-isopropylacrylamide): Experiment, theory and application. Prog. Polym. Sci. 1992, 17, 163-249. [CrossRef]

11. Heskins, M.; Guillet, J.E. Solution Properties of Poly(N-isopropylacrylamide). J. Macromol. Sci. Part A Chem. 1968, 2, 1441-1455. [CrossRef]

12. Huber, S.; Jordan, R. Modulation of the lower critical solution temperature of 2-Alkyl-2-oxazoline copolymers. Colloid Polym. Sci. 2007, 286, 395-402. [CrossRef]

13. Bloksma, M.M.; Paulus, R.M.; Van Kuringen, H.P.C.; Van Der Woerdt, F.; Lambermont-Thijs, H.M.L.; Schubert, U.S.; Hoogenboom, R. Thermoresponsive Poly(2-oxazine)s. Macromol. Rapid Commun. 2011, 33, 92-96. [CrossRef] [PubMed]

14. Hoogenboom, R.; Lambermont-Thijs, H.H.; Jochems, M.J.H.C.; Van Lankvelt, B.M.; Fijten, M.W.M.; Schubert, U.S. Tuning the LCST of poly(2-oxazoline)s by varying composition and molecular weight: Alternatives to poly(N-isopropylacrylamide)? Chem. Commun. 2008, 5758-5760. [CrossRef] [PubMed]

15. Diehl, C.; Schlaad, H. Thermo-Responsive Polyoxazolines with Widely Tuneable LCST. Macromol. Biosci. 2008, 9, 157-161. [CrossRef] [PubMed]

16. Lutz, J.-F. Thermo-Switchable Materials Prepared Using the OEGMA-Platform. Adv. Mater. 2011, 23, 2237-2243. [CrossRef]

17. Fournier, D.D.; Hoogenboom, R.R.; Lambermontthijs, H.M.L.; Paulus, A.R.M.; Schubert, U.S. Tunable pH- and TemperatureSensitive Copolymer Libraries by Reversible Addition-Fragmentation Chain Transfer Copolymerizations of Methacrylates. Macromolecules 2007, 40, 915-920. [CrossRef]

18. Trzebicka, B.; Szweda, D.; Rangelov, S.; Kowalczuk, A.; Mendrek, B.; Utrata-Wesołek, A.; Dworak, A. (Co)polymers of oligo(ethylene glycol) methacrylates-temperature-induced aggregation in aqueous solution. J. Polym. Sci. Part A Polym. Chem. 2012, 51, 614-623. [CrossRef]

19. Zhang, Y.; Furyk, S.; Bergbreiter, A.D.E.; Cremer, P.S. Specific Ion Effects on the Water Solubility of Macromolecules: PNIPAM and the Hofmeister Series. J. Am. Chem. Soc. 2005, 127, 14505-14510. [CrossRef]

20. Magnusson, J.P.; Khan, A.; Pasparakis, G.; Saeed, A.O.; Wang, W.; Alexander, C. Ion-Sensitive “Isothermal” Responsive Polymers Prepared in Water. J. Am. Chem. Soc. 2008, 130, 10852-10853. [CrossRef]

21. Heyda, J.; Dzubiella, J. Thermodynamic Description of Hofmeister Effects on the LCST of Thermosensitive Polymers. J. Phys. Chem. B 2014, 118, 10979-10988. [CrossRef]

22. Hofmeister, F. Zur Lehre von der Wirkung der Salze. Naunyn-Schmiedeberg's Arch. Pharmacol. 2005, 24, 247-260. [CrossRef]

23. Moelbert, S.; Normand, B.; Rios, P.D.L. Kosmotropes and chaotropes: Modelling preferential exclusion, binding and aggregate stability. Biophys. Chem. 2004, 112, 45-57. [CrossRef] [PubMed]

24. Cho, Y.; Zhang, Y.; Christensen, T.; Sagle, L.B.; Chilkoti, A.; Cremer, P.S. Effects of Hofmeister Anions on the Phase Transition Temperature of Elastin-like Polypeptides. J. Phys. Chem. B 2008, 112, 13765-13771. [CrossRef] [PubMed]

25. Du, H.; Wickramasinghe, R.; Qian, X. Effects of Salt on the Lower Critical Solution Temperature of Poly (N-Isopropylacrylamide). J. Phys. Chem. B 2010, 114, 16594-16604. [CrossRef] [PubMed]

26. Bloksma, M.M.; Bakker, D.J.; Weber, C.; Hoogenboom, R.; Schubert, U.S. The Effect of Hofmeister Salts on the LCST Transition of Poly(2-oxazoline)s with Varying Hydrophilicity. Macromol. Rapid Commun. 2010, 31, 724-728. [CrossRef]

27. Jamroz-Piegza, M.; Utrata-Wesołek, A.; Trzebicka, B.; Dworak, A. Hydrophobic modification of high molar mass polyglycidol to thermosensitive polymers. Eur. Polym. J. 2006, 42, 2497-2506. [CrossRef]

28. Nakhmanovich, B.I.; Pakuro, N.I.; Akhmet'Eva, E.I.; Litvinenko, G.I.; Arest-Yakubovich, A.A. Thermal sensitivity of poly(Nvinylpyrrolidone) solutions in water-saline media. Polym. Sci. Ser. B 2007, 49, 136-138. [CrossRef]

29. Gubarev, A.; Monnery, B.D.; Lezov, A.A.; Sedlacek, O.; Tsvetkov, N.V.; Hoogenboom, R.; Filippov, S.K. Conformational properties of biocompatible poly(2-ethyl-2-oxazoline)s in phosphate buffered saline. Polym. Chem. 2018, 9, 2232-2237. [CrossRef]

30. Bruce, E.E.; Bui, P.T.; Rogers, B.A.; Cremer, P.S.; Van Der Vegt, N.F.A. Nonadditive Ion Effects Drive Both Collapse and Swelling of Thermoresponsive Polymers in Water. J. Am. Chem. Soc. 2019, 141, 6609-6616. [CrossRef] 
31. Lipowska-Kur, D.; Szweda, R.; Trzebicka, B.; Dworak, A. Preparation and characterization of doxorubicin nanocarriers based on thermoresponsive oligo(ethylene glycol) methyl ether methacrylate polymer-drug conjugates. Eur. Polym. J. 2018, 109, 391-401. [CrossRef]

32. Szweda, R.; Trzebicka, B.; Dworak, A.; Otulakowski, Ł.; Kosowski, D.; Hertlein, J.; Haladjova, E.; Rangelov, S.; Szweda, D. Smart Polymeric Nanocarriers of Met-enkephalin. Biomacromolecules 2016, 17, 2691-2700. [CrossRef]

33. Kono, K. Thermosensitive polymer-modified liposomes. Adv. Drug Deliv. Rev. 2001, 53, 307-319. [CrossRef]

34. Bae, Y.H.; Okano, T.; Hsu, R.; Kim, S.W. Thermo-sensitive polymers as on-off switches for drug release. Die Makromol. Chem. Rapid Commun. 1987, 8, 481-485. [CrossRef]

35. Nishimori, K.; Maruyama, M.; Shimazaki, Y.; Ouchi, M.; Yoshida, H. Design of Thermoresponsive Polymers Toward Antibody Purification. ACS Appl. Polym. Mater. 2019, 1, 1925-1929. [CrossRef]

36. Nagase, K.; Hasegawa, M.; Ayano, E.; Maitani, Y.; Kanazawa, H. Effect of Polymer Phase Transition Behavior on TemperatureResponsive Polymer-Modified Liposomes for siRNA Transfection. Int. J. Mol. Sci. 2019, 20, 430. [CrossRef]

37. Longenecker, R.; Mu, T.; Hanna, M.; Burke, N.A.D.; Stöver, H.D.H. Thermally Responsive 2-Hydroxyethyl Methacrylate Polymers: Soluble-Insoluble and Soluble-Insoluble-Soluble Transitions. Macromolecules 2011, 44, 8962-8971. [CrossRef]

38. Lavigueur, C.; García, J.G.; Hendriks, L.; Hoogenboom, R.; Cornelissen, J.J.L.M.; Nolte, R.J.M. Thermoresponsive giant biohybrid amphiphiles. Polym. Chem. 2011, 2, 333-340. [CrossRef]

39. Kasprów, M.; Machnik, J.; Otulakowski, Ł.; Dworak, A.; Trzebicka, B. Thermoresponsive P(HEMA-co-OEGMA) copolymers: Synthesis, characteristics and solution behavior. RSC Adv. 2019, 9, 40966-40974. [CrossRef]

40. Wałach, W.; Oleszko-Torbus, N.; Utrata-Wesołek, A.; Bochenek, M.; Kijeńska-Gawrońska, E.; Górecka, Ż.; Święszkowski, W.; Dworak, A. Processing of (Co)Poly(2-oxazoline)s by Electrospinning and Extrusion from Melt and the Postprocessing Properties of the (Co)Polymers. Polymers 2020, 12, 295. [CrossRef]

41. Lutz, J.-F.; Börner, H.G. Modern trends in polymer bioconjugates design. Prog. Polym. Sci. 2008, 33, 1-39. [CrossRef]

42. Huang, C.-J.; Chang, F.-C. Polypeptide Diblock Copolymers: Syntheses and Properties of Poly(N-isopropylacrylamide)-bPolylysine. Macromolecules 2008, 41, 7041-7052. [CrossRef]

43. Trzebicka, B.; Robak, B.; Trzcinska, R.; Szweda, R.; Suder, P.; Silberring, J.; Dworak, A. Thermosensitive PNIPAM-peptide conjugate-Synthesis and aggregation. Eur. Polym. J. 2013, 49, 499-509. [CrossRef]

44. Kokardekar, R.; Shah, V.; Mody, H. PNIPAM Poly (N-isopropylacrylamide): A Thermoresponsive "Smart" Polymer in Novel Drug Delivery Systems. Internet J. Med. Update EJOURNAL 2012, 7, 60-63.

45. Molawi, K.; Studer, A. Reversible switching of substrate activity of poly-N-isopropylacrylamide peptide conjugates. Chem. Commun. 2007, 5173-5175. [CrossRef] [PubMed]

46. Ohnsorg, M.L.; Ting, J.M.; Jones, S.D.; Jung, S.; Bates, F.S.; Reineke, T.M. Tuning PNIPAm self-assembly and thermoresponse: Roles of hydrophobic end-groups and hydrophilic comonomer. Polym. Chem. 2019, 10, 3469-3479. [CrossRef]

47. Luo, Y.-L.; Yang, X.-L.; Xu, F.; Chen, Y.-S.; Zhang, B. Thermosensitive PNIPAM-b-HTPB block copolymer micelles: Molecular architectures and camptothecin drug release. Colloids Surfaces B Biointerfaces 2014, 114, 150-157. [CrossRef]

48. Oleszko-Torbus, N.; Utrata-Wesołek, A.; Bochenek, M.; Lipowska-Kur, D.; Dworak, A.; Wałach, W. Thermal and crystalline properties of poly(2-oxazoline)s. Polym. Chem. 2020, 11, 15-33. [CrossRef]

49. Rettler, E.F.-J.; Kranenburg, J.M.; Lambermont-Thijs, H.M.; Hoogenboom, R.; Schubert, U.S. Thermal, Mechanical, and Surface Properties of Poly(2-N -alkyl-2-oxazoline)s. Macromol. Chem. Phys. 2010, 211, 2443-2448. [CrossRef]

50. Demirel, A.L.; Güner, P.T.; Verbraeken, B.; Schlaad, H.; Schubert, U.S.; Hoogenboom, R. Revisiting the crystallization of poly(2alkyl-2-oxazoline)s. J. Polym. Sci. Part B Polym. Phys. 2015, 54, 721-729. [CrossRef]

51. Litt, M.; Rahl, F.; Roldan, L.G. Polymerization of cyclic imino ethers. VI. X-ray study of some polyaziridines. J. Polym. Sci. Part A-2 Polym. Phys. 2003, 7, 463-473. [CrossRef]

52. Trzebicka, B.; Haladjova, E.; Otulakowski, Ł.; Oleszko, N.; Wałach, W.; Libera, M.; Rangelov, S.; Dworak, A. Hybrid nanoparticles obtained from mixed mesoglobules. Polymers 2015, 68, 65-73. [CrossRef]

53. Bolisetty, S.; Schneider, C.; Polzer, F.; Ballauff, M.; Li, W.; Zhang, A.; Schlüter, A.D. Formation of Stable Mesoglobules by a Thermosensitive Dendronized Polymer. Macromolecules 2009, 42, 7122-7128. [CrossRef]

54. Wu, C.; Li, W.; Zhu, X.X. Viscoelastic Effect on the Formation of Mesoglobular Phase in Dilute Solutions. Macromolecules 2004, 37, 4989-4992. [CrossRef]

55. Weda, P.; Trzebicka, B.; Dworak, A.; Tsvetanov, C. Thermosensitive nanospheres of low-density core-An approach to hollow nanoparticles. Polymers 2008, 49, 1467-1474. [CrossRef]

56. Haladjova, E.; Rangelov, S.; Tsvetanov, C.; Simon, P.F.W. Preparation of polymeric nanocapsules via nano-sized poly(methoxydiethyleneglycol methacrylate) colloidal templates. Polymers 2014, 55, 1621-1627. [CrossRef] 